\title{
ANALISIS KALIMAT IMPERATIF PADA TUTURAN MASYARAKAT DESA TELUK RAYA KECAMATAN KUMPEH KABUPATEN MUARO JAMBI (KAJIAN PRAGMATIK)
}

\author{
Sainil Amral ${ }^{1}$, Siti Dian Ulfah ${ }^{2}$ \\ Program Studi Pendidikan Bahasa dan Sastra Indonesia, \\ Fakultas Keguruan dan Ilmu Pendidikan, Universitas Batanghari, \\ Jambi
}

amralsainil@gmail.com

dulfah28@yahoo.com

\begin{abstract}
The purpose of this research is to describe the form imperative sentences in the oral speech of the Teluk Raya village society, Kumpeh Regency Muaro Jambi (A Pragmatic study). This research is descriptive qualitative. The primary data is taken from the Imperative sentences (order) of Malay Jambi Kumpeh language on the community of Teluk Raya Village Kumpeh Muaro Jambi district, while the secondary data is derived from books. In collecting the data, uninvolved conversation observation technique, note-taking technique, and interview technique are used. Based on the results of the data analysis, it can be concluded that there are five imperative sentences of the Jambi Malay Kumpeh language. They are ordinary imperative sentence, request imperative sentence, granting permit imperative sentence, ask and order imperative sentence. Moreover, there are also three kinds of speech acts occur in the Jambi Malay language, they are locutionary, illocutionary, and perlocutionary.
\end{abstract}

Keywords: Imperative Sentence, Verbal Utterance, Pragmatics

${ }^{1}$ Dosen Program Studi Pendidikan Bahasa dan Sastra Indonesia, Fakultas Keguruan dan Ilmu Pendidikan, Universitas Batanghari, Jambi

${ }^{2}$ Mahasiswa Program Studi Pendidikan Bahasa dan Sastra Indonesia, Fakultas Keguruan dan Ilmu Pendidikan, Universitas Batanghari, Jambi

Analisis Kalimat Imperatif pada Tuturan Masyarakat Desa Teluk Raya Kecamatan Kumpeh Kabupaten Muaro Jambi (Kajian Pragmatik) 


\section{PENDAHULUAN}

Pada umumnya di dalam kehidupan sehari-hari masyarakat selalu berbicara untuk berinteraksi kepada masyarakat lainnya. Masyarakat tersebut menggunakan bahasa sebagai alat untuk berkomunikasi. Hal tersebut senada dengan pendapat Rofii dan Hasibuan (2019) bahwa Fungsi bahasa yang paling mendasar ialah sebagai alat komunikasi. Begitu juga dengan penduduk Desa Teluk Raya Kecamatan Kumpeh Kabupaten Muaro Jambi dari zaman dahulu hingga sekarang masih menggunakan bahasa Melayu Jambi Kumpeh sebagai alat untuk berkomunikasi sehari-hari. Selain untuk berkomunikasi bahasa juga berguna untuk menyampaikan informasi, mengutarakan pikiran, serta perasaan. Bahasa seseorang mencerminkan pikirannya. Oleh karena itu, semakin terampil seseorang berbahasa semakin cerah dan jelas pula jalan pikirannya.

Setiap keterampilan berbahasa memiliki keterkaitan satu dengan yang lain. Keterampilan berbicara memiliki keterkaitan dengan bahasa lisan. Dengan adanya bahasa lisan maka komunikasi dapat terjadi antara penutur dan mitra tutur. Dalam sebuah tindak tutur, penutur menyampaikan maksud perkataannya. Penutur mengatakan hal yang diharapkan mitra tutur dapat memahami maksud penutur. Tuturan lisan merupakan suatu tuturan yang berisi informasi yang diperoleh secara langsung. Salah satu ilmu yang mempelajari tentang tuturan adalah pragmatik.

Pragmatik merupakan suatu kajian ilmu tentang penggunaan bahasa dalam tindak komunikasi yang mengaitkan antara tuturan dan penutur dengan konteks situasi tuturnya. Dapat kita ketahui bahwa di dalam pragmatik terdapat tindak tutur yang terdiri dari tiga tindak tutur yaitu tindak tutur lokusi, tindak tutur ilokusi dan tidak tutur perlokusi. Suatu tuturan dapat dipahami secara mendalam maksud tuturannya dengan menggunakan kajian pragmatik. Oleh sebab itu, pemahaman tuturan tidak bisa dipahami secara struktural saja, melainkan juga secara pragmatik. Hal tersebut dilakukan untuk mengetahui fungsi pragmatik imperatif pada suatu tuturan kalimat imperatif yang terdapat dalam tuturan masyarakat Desa Teluk Raya Kecamatan Kumpeh Kabupaten Muaro Jambi.

Untuk mengetahui fungsi pragmatik imperatif pada suatu tuturan kalimat imperatif maka diperlukan pemahalan mengenai kalimat. Kalimat merupakan satuan bahasa yang berupa rangkaian kata dan dapat menyatakan makna baik secara lisan maupun tulisan serta digunakan untuk berkomunikasi. Kalimat adalah ungkapan pesan atau informasi, dan pikiran yang memiliki intonasi final (Rofii, 2015: 22).

Kalimat mempunyai banyak ragam salah satunya yaitu kalimat imperatif. Kalimat imperatif adalah kalimat yang berfungsi memerintahkan lawan bicara untuk melakukan apa yang diminta atau diinginkan oleh pembicara. Banyak hal yang harus diperhatikan dalam menyampaikan kalimat imperatif, termasuk pada siapa kalimat imperatif digunakan, dalam situasi yang bagaimana kalimat imperatif digunakan, bagaimana hubungan antara pembicara dan lawan bicara pada saat kalimat imperatif digunakan dan bagaimana respon lawan bicara terhadap kalimat imperatif yang disampaikan padanya.

Menurut Rahardi (2005: 79) kalimat imperatif bahasa Indonesia terbagi menjadi lima macam yakni kalimat imperatif biasa, kalimat imperatif permintaan, kalimat imperatif pemberian 
izin, kalimat imperatif ajakan dan kalimat imperatif suruhan. Kalimat walau hanya terdiri dari satu kata saja, tetapi apabila penutur dan mitra tutur memiliki pengertian yang sama tentang makna yang ingin disampaikan maka komunikasipun dapat terjadi.

Dalam kehidupan sehari-hari, masyarakat Desa Teluk Raya Kecamatan Kumpeh Kabupaten Muaro Jambi masih menggunakan kalimat imperatif untuk berinteraksi. Penggunaan kalimat imperatif sering kali didengar, dan dilakukan dalam kehidupan sehari-hari di lingkungan masyarakat Desa teluk Raya. Anggota masyarakat sering memerintahkan anggota masyarakat yang lain untuk melakukana sesuatu dengan kalimat perintah. Hal tersebut dilakukan karena komunikasi tersebut terbilang sederhana dan mudah dilakukan. Kalimat yang dipakai masyarakat tersebut sungguh unik dan mempunyai ciri khas tersendiri, berbeda dari desa-desa yang lainnya baik dari segi bahasa, pengucapan, hingga struktur kalimatnya.

$$
\text { Masyarakat bertutur }
$$
menggunakan kalimat imperatif kepada mitra tutur dengan maksud tertentu agar mitra tutur melakukan sesuatu sesuai maksud dan tujuan si penutur. Semua peristiwa tutur dipengaruhi oleh situasi dan kondisi di sekitarnya. Ragam bahasa yang dituturkan melalui alat ucap merupakan suatu bentuk komunikasi yang disebut dengan tuturan lisan. Situasi dan kondisi ini dipengaruhi oleh beragam jenis keterampilan bahasa daerah, salah satunya yaitu bahasa Melayu Jambi Kumpeh yang berada di Desa Teluk Raya Kecamatan Kumpeh Kabupaten Muaro Jambi.

Berdasarkan observasi awal yang telah dilakukan terhadap masyarakat Kumpeh dalam berkomunikasi seharihari, diketahui bahwa mereka masih menggunakan bahasa Melayu Jambi Kumpeh. Observasi juga dilakukan terhadap kaum remaja di desa tersebut. hasil observasi terhadap kaum remaja menunjukkan bahwa sebagian remaja di desa tersebut sudah tidak mau lagi memakai bahasa Melayu Jambi Kumpeh. Mereka menganggap bahwa bahasa Melayu Jambi Kumpeh tersebut ketinggalan zaman. Padahal bahasa Melayu Jambi Kumpeh adalah bahasa yang sejak zaman dahulu sudah ada.

Perkembangan zaman dan teknologi yang semakin maju, faktor lingkungan, serta masuknya pendatang dari daerah lain yang tinggal di daerah Kumpeh, mengakibatkan kaum remaja di daerah Kumpeh enggan berkomunikasi menggunakan bahasa Melayu daerah Kumpeh, mereka biasanya memakai bahasa Indonesia. Seharusnya sebagai masyarakat asli Kumpeh mereka sebaiknya tidak melupakan bahasa desa mereka sendiri, karena bahasa Melayu Jambi Kumpeh merupakan suatu kebudayaan dan ciri khas masyarakat Kumpeh. Jika bahasa Melayu Jambi Kumpeh tidak lagi dipakai dalam kehidupan sehari-hari maka akan punah dan generasi penerus yang akan datang tidak akan mengetahui lagi bahasa Melayu Jambi Kumpeh.

Berdasarkan paparan tersebut, dan dalam rangka membina, melestarikan sekaligus mengembangkan bahasa Melayu Jambi dialek Kumpeh pada masyarakat Desa Teluk Raya Kecamatan Kumpeh Kabupaten Muaro Jambi, maka penelitian ini perlu dilakukan. Penelitian ini dilakukan dengan judul analisis bentuk kalimat imperatif dalam tuturan lisan masyarakat Desa Teluk Raya Kecamatan Kumpeh Kabupaten Muaro Jambi Tahun 2019 (Kajian Pragmatik).

Fokus penelitian ini ialah mendeskripsikan analisis bentuk kalimat 
imperatif biasa, permintaan, pemberian izin, ajakan dan suruhan dalam tuturan lisan masyarakat Desa Teluk Raya Kecamatan Kumpeh Kabupaten Muaro Jambi tahun 2019 (kajian pragmatik) dalam kehidupan sehari-hari.

Adapun pertanyaan penelitian dirumuskan sebagai berikut. Bagaimanakah bentuk kalimat imperatif biasa, permintaan, pemberian izin, ajakan dan suruhan dalam tuturan lisan masyarakat Desa Teluk Raya Kecamatan Kumpeh Kabupaten Muaro Jambi?

Tujuan penelitian ini adalah untuk mendeskripsikan bentuk kalimat imperatif biasa, permintaan, pemberian izin, ajakan, dan suruhan dalam tuturan lisan masyarakat Desa Teluk Raya Kecamatan Kumpeh Kabupaten Muaro Jambi.

\section{Kajian Pustaka}

Bahasa adalah alat yang digunakan untuk berkomunikasi dalam kehidupan sehari-hari untuk menyampaikan gagasan atau perasaan. Ilmu yang mengkaji tentang bahasa adalah linguistik. Linguistik berasal dari kata latin yaitu lingua yang berarti bahasa. Orang yang ahli dalam ilmu linguistik atau pakar linguistik disebut linguis. Menurut Kridalaksana (dalam Chaer 2007: 32) "Bahasa adalah suatu sistem sistematis bersifat arbitrer, digunakan oleh suatu masyarakat tutur untuk bekerja sama, berkomunikasi, dan mengidentifikasi diri". Bahasa adalah alat komunikasi yang dengannya manusia dapat menyampaikan pikiran dan perasaan kepada orang lain secara lebih tepat. Fungsi bahasa sangat berkaitan dengan kebudayaan yang didukung bahasa itu sendiri. Menurut Keraf (dalam Finoza, 2008:2) merumuskan fungsi bahasa secara umum ada empat yaitu:

a. Sebagai alat berkomunikasi. b. Sebagai alat mengekspresikan diri.

c. Sebagai alat berintegrasi dan beradaptasi sosial.

d. Sebagai alat kontrol sosial.

Suatu bahasa memiliki ragam

bahasa. Ragam bahasa adalah variasi

bahasa menurut pemakaian yang berbeda-beda menurut topik yang dibicarakan, menurut hubungan pembicara, kawan bicara, orang yang dibicarakan, serta menurut medium pembicara Bachman (dalam Damayanti dan Indrayanti, 2015: 15-16).

Menurut Finoza (2008: 5) "Ragam bahasa adalah variasi bahasa yang terjadi karena pemakaian bahasa. Berdasarkan media pengantarnya ragam bahasa terdiri dari ragam bahasa lisan dan ragam bahasa tulis". Menurut Finoza (2008: 7) "Ragam bahasa lisan tindakan yang menghendaki adanya lawan bicara untuk berbicara". Ragam bahasa lisan maknanya dipengaruhi oleh tinggi rendah dan panjang pendeknya nada suara. Di dalam ragam lisan tentunya berkaitan dengan tuturan lisan atau bahasa lisan menurut Pateda (2015: 13) tuturan lisan merupakan ujaran yang keluar dari alat ucap manusia secara langsung. Tuturan lisan sangat sering digunakan manusia untuk berinteraksi dalam kehidupan sehari-hari. Menurut Efendi (dalam Pateda, 2015: 15) berpendapat bahwa tuturan lisan atau bahasa lisan sangat berbeda dengan bahasa tulis karena tuturan lisan diucapkan dengan tekanan, nada, irama, jeda, atau lagu tertentu untuk memperjelas makna dan maksud tuturan. Selain itu kalimat yang dituturkan tidak selalu merupakan kalimat yang lengkap, di dalam kehidupan sehari-hari menunjukan bahwa tuturan lisan lebih sering digunakan untuk berinteraksi.

Ragam bahasa tulis adalah ragam bahasa yang digunakan melalui media

Analisis Kalimat Imperatif pada Tuturan Masyarakat Desa Teluk Raya Kecamatan Kumpeh

Kabupaten Muaro Jambi (Kajian Pragmatik) 
tulis, tidak terikat ruang dan waktu sehingga diperlukan kelengkapan struktur sampai pada sasaran secara visual. Menurut Widjono (2007: 23) "Ragam bahasa tulis ditandai dengan kecermatan menggunakan ejaan dan tanda baca, kosa kata, penggunaan tata bahasa dalam pembentukan kata, penyusunan kalimat, paragraf dan wacana".

Dapat kita ketahui bahwa bahasa merupakan suatu kajian ilmu dari bidang linguistik. Salah satu bidang ilmu yang terbagi dalam linguistik adalah pragmatik. Yule (dalam terj. Wahyuni 2006: 3) "Pragmatik adalah studi tentang makna yang disampaikan oleh penutur (atau penulis) ditafsirkan oleh pendengar (atau pembaca). Pada ilmu pragmatik terdapat sebuah tindak tutur.

Menurut Levinson (dalam Rahardi, Styaningsih dan Dewi, 2016:17) mencatat bahwa "Pragmatik adalah telaah segala aspek makna yang tidak tercakup dalam semantik. Jadi, dalam pandangannya, pragmatik memperbincangkan segala aspek makna ucapan yang tidak dapat dijelaskan secara tuntas oleh referensi langsung pada kebenaran kalimat yang diucapkan".

Menurut Tarigan (dalam Rahardi dkk, 2016:18) "Pragmatik adalah telaah umum mengenai bagaimana konteks memengaruhi cara kita menafsirkan kalimat, teori tindak ujar bagian dari pragmatik sendiri merupakan bagian dari performasi linguistik. Pragmatik mencakup bagaimana cara pemakai bahasa menerapkan pengetahuan dunia untuk menginterprestasikan ucapanucapan".

Sedangkan menurut Leech (dalam Rahardi dkk, 2016:19) "menyatakan bahwa "Pragmatik berinteraksi dalam linguistik khususnya dengan sintaksis dan semantik. Fonologi, sintaksis dan semantik dapat disebut tata bahasa, sedangkan pragmatik disebut penggunaan tata bahasa".

Di dalam pragmatik maksud penutur atau dapat juga disebut sebagai makna. Pragmatik mengkaji maksud penutur dalam menuturkan sebuah satuan lingual tertentu pada klausa. "Pragmatik mengkaji makna secara eksternal dan pragmatik itu hanya dapat dimaknai dengan mendasarkan dan memperhitungkan konteksnya" (Rahardi, 2005: 50). Fenomena-fenomena kebahasaan yang dipelajari di dalam pragmatik antara lain yaitu deiksis, dan implikatur.

Menurut Alwi (dalam Rahardi dkk, 2016: 88) "Deksis merupakan gejala semantik yang terdapat pada kata atau konstruksi yang hanya dapat ditafsirkan acuannya dengan memperhitungkan situasi pembicaraan". "Deiksis adalah salah satu hal mendasar yang dilakukan dengan tuturan, deiksis berarti "penunjukan" melalui bahasa" Yule (dalam terj. Wahyuni, 2006:13). Menurut Kridalaksana (dalam Rahardi dkk, 2016: 88) "Deiksis adalah hal atau fungsi yang menunjuk sesuatu di luar bahasa". Deiksis merupakan kata-kata yang memiliki referen yang berubah-ubah atau berpindah-pindah. Sebuah kata dikatakan bersifat deiksis apabila referennya berpindah-pindah atau berganti-ganti, tergantung pada siapa yang menjadi pembicara dan tergantung pula pada saat dan tempat dituturkannya.

Implikatur adalah kesantunan dalam berbahasa. Menurut Wijana (dalam Rahardi dkk, 2016: 86) menyebutkan bahwa "Sebuah tuturan dapat dikatakan mengimplikasikan proposisi atau maksud yang bukan merupakan bagian dari tuturan yang bersangkutan. Proposisi atau maksud yang diimplikasikan itulah yang disebut sebagai implikatur". Grice (dalam 
Rahardi dkk, 2016: 74 mengatakan bahwa) "Implikatur adalah sebuah tuturan dapat mengimplikasikan proposisi yang tidak merupakan bagian dari tuturan tersebut.

Tuturan yang berbunyi "Bapak datang, jangan menangis!” tidak sematamata dimaksudkan untuk memberitahukan bahwa sang ayah sudah datang dari tempat tertentu. Si penutur bermaksud memperingatkan mitra tutur, bahwa sang ayah yang bersikap keras dan biasa bertindak kejam itu akan melakukan sesuatu terhadapnya apabila dia masih terus menangis. Dengan perkataan lain, tuturan itu mengimplikasikan bahwa sang ayah adalah orang yang keras dan sangat kejam, sering marah-marah pada anaknya yang sedang menangis".

Menurut Rahardi (2005: 43) menjelaskan bahwa "Implikatur merupakan hubungan antara tuturan yang sesungguhnya dengan maksud yang tidak dituturkan itu bersifat tidak mutlak, dan didasarkan pada konteks situasi tutur yang mewadani munculnya tuturan". Dalam implikatur jika dua orang bercakap-cakap, percakapan itu dapat berlangsung dengan lancar berkat adanya semacam kesepakatan bersama. Kesepakatan itu antara lain, berupa kontrak tak tertulis bahwa ihwal yang dibicarakan itu harus saling berhubungan atau berkaitan".

Implikatur merupakan kesantunan dalam berbicara. Ternyata dalam kehidupan sehari-hari, khususnya dalam percakapan umumnya dari ucapan yang dikeluarkan oleh pelaku tindak berbahasa mengandung makna. Oleh karena itu, pendengar harus mampu menetapkan bahwa ada makna atau maksud lain dibalik ucapan yang telah dikeluarkan pembicara itu. Dengan demikian, secara efektif pendengar dapat memberi respon atau tanggapan yang sesuai dengan implikatur yang muncul.

Untuk dapat menentukan apa yang dimaksud dibalik apa yang dikatakan diperlukan pengetahuan tentang kaidah pragmatiknya, dengan kata lain, untuk menentukan implikatur suatu ucapan kita harus memahami apa kaidah pragmatiknya melalui tindak tutur.

Telah dijelaskan bahwa tindak tutur merupakan suatu tuturan yang disampaikan oleh penutur kepada mitra tutur. Menurut Yule (dalam terj. Wahyuni, 2006: 83-84) "Tindak tutur terbagi menjadi tiga yaitu, tindak lokusi yang merupakan tindak dasar dalam tuturan, ilokusi, dan tidak perlokusi".

Menurut Searle (dalam Rahardi dkk, 2016: 77) "Tindak tutur adalah tuturan yang disampaikan oleh penutur terhadap mitra tutur, di dalam pragmatik terbagi menjadi tiga macam tindak tutur lokusi, ilokusi dan perlokusi”. Menurut Austin (dalam terj. Oka, 2015: 316 mengatakan bahwa) "Ada tiga jenis tindak tutur yaitu tindak lokusi (melakukan tindakan mengatakan sesuatu), ilokusi (melakukan tindakan dalam melakukan sesuatu), dan perlokusi (melakukan tindakan dengan mengatakan sesuatu)".

Adapun pada penelitian ini peneliti meneliti tentang tuturan yang berkaitan pada ilmu pragmatik dan kalimat salah satunya yaitu kalimat imperatif (kalimat perintah atau suruhan) yang kita ketahui bahwa kalimat merupakan satuan bahasa terkecil dalam wujud lisan atau tulisan, yang menggungkapkan pikiran yang utuh. Menurut Ramlan (2005:23) Kalimat adalah satuan gramatik yang dibatasi oleh adanya jeda panjang yang disertai nada akhir turun atau naik. Suatu kalimat dibentuk oleh beberapa unsur, unsur- 
unsur tersebut disebut subjek, predikat, objek, pelengkap dan keterangan (Kosasih, 2010: 64).

Pada suatu kalimat terdapat jenisjenis kalimat yaitu kalimat imperatif, introgatif, deklaratif, ekslamatif. Dalam penelitian ini, difokuskan pada kalimat imperatif. Menurut Alwi dkk, (2003: 361) menjelaskan bahwa kalimat imperatif adalah kalimat perintah atau suruhan dan permintan. Sedangkan menurut Rahardi (2005:79-83) mengklasifikan kalimat imperatif bahasa Indonesia secara formal menjadi lima macam yaitu kalimat imperatif biasa, permintaan, pemberian izin, ajakan dan suruhan. Pada penelitian ini peneliti menggunakan teori Rahardi (2005: 7983) yang mengenai kalimat imperatif sebagai acuan dalam penelitian ini.

\section{METODE PENELITIAN}

Jenis penelitian ini adalah penelitian deskriptif kualitatif. Kerlinger (dalam Mahsun, 2007:2) "penelitian adalah suatu hal yang ilmiah maksudnya penelitian yang sistematis, terkontrol, empiris, dan kritis terhadap proposisiproposisi hipotetis tentang hubungan yang diperkirakan terdapat antar gejala alam". Metode penelitian bahasa digunakan untuk mempermudah dalam melakukan suatu penelitian khususnya bahasa yang dapat digunakan dalam metode tersebut.

"Penelitian kualitatif adalah penelitian yang menggambarkan keadaan objek penelitian berdasarkan fakta-fakta yang sebenarnya. Penelitian kualitatif digunakan sebagai bahan untuk mendapatkan data yang mendalam dan suatu data yang mengandung makna yang sebenarnya" (Sugiyono, 2007:15). "Penelitian kualitatif adalah penelitian yang yang bermaksud untuk memahami fenomena tentang apa yang dialami oleh subjek penelitian" (Moleong, 2017: 6).

Data dalam penelitian ini berupa data primer dan data skunder. Data primer merupakan data utama yang sangat penting dalam sebuah penelitian. "Data primer adalah bukti penulisan yang diperoleh di lapangan yang dilakukan secara langsung oleh penulisnya (Widjono, 2007: 248)". Data primer penelitian ini diambil dari hasil rekaman wawancara tuturan lisan kalimat imperatif bahasa Melayu Jambi Kumpeh pada masyarakat Desa Teluk Raya Kecamatan Kumpeh Kabupaten Muaro Jambi, selanjutnya rekaman ini penulis transkripkan ke dalam teks. Sedangkan data skunder merupakan data yang diperoleh secara tidak langsung atau melalui perantara.

"Data skunder adalah bukti teoretik yang diperoleh melalui studi pustaka" Widjono (2007:248). Data skunder dalam penelitian ini adalah buku-buku yang berhubungan dengan teori kalimat imperatif bahasa Melayu Jambi.

Pengumpulan data dalam penelitian ini menggunakan teknik observasi, teknik simak bebas libat cakap, teknik catat dan teknik wawancara yang difokuskan untuk menganalisis bentuk kalimat imperatif bahasa Melayu Jambi Kumpeh dalam tuturan lisan masyarakat Desa Teluk Raya Kecamatan Kumpeh Kabupaten Muaro Jambi.

Teknik analisis data dilakukan setelah data terkumpul, langkah yang dilakukan selanjutnya ialah mengolah data dengan cara mendeskripsikannya. Analisis data dilakukan dengan mengorganisasikan data, menjabarkan kedalam unit-unit, melakukan sintesa, menyusun kedalam pola memilih mana yang penting dan yang akan dipelajari yaitu suatu analisa berdasarkan data yang 
diperoleh, selanjutnya dikembangkan menjadi hipotesis (Sugiyono, 2007: 335).

Penelitian ini menggunakan

konsep Sugiyono (2007: 338) yaitu rekduksi data, data dikelompokkan berdasarkan aspek-aspek yang diteliti sesuai dengan jenis dan dimasukkan ke dalam tabel tabulasi data. Penyajian data yaitu data diinterpretasikan sesuai dengan kerangka teori. Data dianalisis menggunakan metode deskriptif, dan penarikan kesimpulan yaitu kesimpulan dari langkah-langkah penelitian yang telah dilakukan.

\section{HASIL DAN PEMBAHASAN}

Berdasarkan analisis data yang telah dilakukan terhadap kalimat imperatif bahasa Melayu Jambi Kumpeh di Desa Teluk Raya Kecamatan Kumpeh Kabupaten Muaro Jambi, ditemukan beberapa kalimat imperatif (perintah) dalam Bahasa Melayu Jambi Kumpeh. Kalimat imperatif tersebut di pakai oleh masyarakat Desa Teluk Raya untuk berkomunikasi.

Penelitian kalimat imperatif ini menggunakan pendapat Rahardi (2005: 79-83) sebagai pedoman, bahwa kalimat imperatif terbagi menjadi lima yaitu, kalimat imperatif biasa, kalimat imperatif permintaan, kaimat imperatif pemberian izin, kalimat imperatif ajakan, dan kalimat imperatif suruhan. Selain itu, penelitian ini juga menggunakan pendapat Yule (dalam terj. Wahyuni, 2006: 83-84) bahwa tindak tutur terbagi menjadi tiga yaitu, lokusi, ilokusi, dan perlokusi. Dari hasil penelitian diperoleh tuturan kalimat imperatif bahasa Melayu Jambi Kumpeh yang dapat dicontohkan pada kutipan-kutipan berikut.

\section{Kalimat Imperatif Biasa}

Kutipan 1

\section{- Cocolah lampu tu!}

(Pasanglah lampu itu!)

Kalimat cocolah lampu tu! pada kutiapn 1 tersebut merupakan tuturan lisan bahasa Melayu Jambi Kumpeh, berpratikel pengeras- lah, sesuai dengan pendapat Rahardi (2005:79). Cocolah yang berarti pasanglah, dan lampu tu yang berarti lampu itu. Jadi, pemakaian partikel-lah pada kata "cocolah" merupakan penanda bahwa kalimat tersebut termasuk kalimat imperatif biasa. Pada kalimat tersebut terdapat lokusi yaitu penutur mengatakan agar memasang lampu dan ilokusi pada kalimat tersebut yaitu penutur menyuruh mitra tutur agar memasang lampu.

Pada kalimat cocolah lampu tu! terdapat lokusi yaitu penutur mengatakan agar memasang lampu dan ilokusi pada kalimat tersebut yaitu penutur menyuruh mitra tutur agar memasang lampu. Sedangkan lokusi dan ilokusi pada kalimat tersebut menuntut terjadinya perlokusi, dimana mitra tutur diminta untuk melakukan perintah oleh penutur. Hal ini sesuai dengan teori Yule (dalam terj. Wahyuni, 2006: 83-84) yang mengatakan bahwa perlokusi adalah suatu tindak tutur untuk mempengaruhi mitra tutur untuk melakukan sesuatu.

\section{Kalimat Imperatif Permintaan}

Kutipan 2

- Pek tolonglah ambeki keminang nyai tu!

- (Pek tolong ambilkan tempat sirih nenek!)

Pada kutipan 2 terdapat kalimat Pek, tolonglah ambeki keminang nyai tu! merupakan tuturan lisan bahasa Melayu Jambi Kumpeh, ditandai dengan penanda kesantunan tolong, sesuai dengan pendapat Rahardi (2005: 80). Pek yang

Analisis Kalimat Imperatif pada Tuturan Masyarakat Desa Teluk Raya Kecamatan Kumpeh

Kabupaten Muaro Jambi (Kajian Pragmatik) 
berarti panggilan untuk anak perempuan, tolonglah berarti tolong, ambeki berarti ambilkan, keminang berarti tempat sirih, dan nyai tu berarti nenek. Jadi, pemakaian penanda kesantunan tolong pada kalimat "Pek, tolong ambeki keminang nyai tu!" merupakan penanda bahwa kalimat tersebut termasuk kalimat imperatif permintaan.

Pada kalimat Pek, tolonglah ambeki keminang nyai tu! terdapat lokusi yaitu penutur mengatakan agar mengambil tempat sirih, sedangkan ilokusi pada kalimat tersebut yaitu penutur menyuruh mitra tutur mengambil tempat sirih. Lokusi dan ilokusi pada kalimat tersebut menuntut terjadinya perlokusi, dimana mitra tutur diminta untuk melakukan perintah oleh penutur. Hal ini sesuai dengan teori Yule (dalam terj. Wahyuni, 2006: 83-84) yang mengatakan bahwa perlokusi adalah suatu tindak tutur untuk mempengaruhi mitra tutur untuk melakukan sesuatu.

\section{Kalimat Imperatif Pemberian Izin}

Kutipan 3

- Minumlah aek tu!

- (Silahkan minum!)

Pada kutipan 3 terdapat kalimat minumlah aek tu! merupakan tuturan lisan bahasa Melayu Jambi Kumpeh, ditandai dengan penanda kesantunan silakan, sesuai dengan pendapat Rahardi (2005: 81). Minumlah aek tu yang berarti silahkan minum. Jadi, pemakaian penanda kesantunan silakan pada kalimat "minumlah aek tu!" merupakan penanda bahwa kalimat tersebut termasuk kalimat imperatif pemberian izin.

Pada kalimat minumlah aek tu! terdapat lokusi yaitu penutur mengatakan mengizinkan untuk minum, sedangkan ilokusi pada kalimat tersebut yaitu penutur menyuruh mitra tutur agar minum. Lokusi dan ilokusi pada kalimat tersebut menuntut terjadinya perlokusi, dimana mitra tutur diminta untuk melakukan perintah oleh penutur. Hal ini sesuai dengan teori Yule (dalam terj. Wahyuni, 2006: 83-84) yang mengatakan bahwa perlokusi adalah suatu tindak tutur untuk mempengaruhi mitra tutur untuk melakukan sesuatu.

\section{Kalimat Imperatif Ajakan}

Kutipan 4

- Payo makan!

- (Ayo kita makan dulu!)

Pada Kutipan 4 terdapat kalimat payo makan! merupakan tuturan lisan bahasa Melayu Jambi Kumpeh, ditandai dengan penanda kesantunan ayo, sesuai dengan pendapat Rahardi (2005: 82). Payo yang berarti ayo, dan makan berarti makan. Jadi, pemakaian penanda kesantunan ayo pada kalimat "payo makan!" merupakan penanda bahwa kalimat tersebut termasuk kalimat imperatif ajakan. Pada kalimat tersebut terdapat lokusi yaitu penutur mengatakan untuk mengajak makan, sedangkan ilokusi pada kalimat tersebut yaitu penutur menyuruh mitra tutur agar mau makan.

Pada kalimat payo makan! terdapat lokusi yaitu penutur mengatakan untuk mengajak makan sedangkan ilokusi pada kalimat tersebut yaitu penutur menyuruh mitra tutur agar mau makan. Lokusi dan ilokusi pada kalimat tersebut menuntut terjadinya perlokusi, dimana mitra tutur diminta untuk melakukan perintah oleh penutur. Hal ini sesuai dengan teori Yule (dalam terj. Wahyuni, 2006: 83-84) yang mengatakan bahwa perlokusi adalah suatu tindak tutur untuk mempengaruhi mitra tutur untuk melakukan sesuatu. 


\section{Kalimat Imperatif Suruhan}

Kutipan 5

- Cobo kau tengok sapo tu!

- (Coba kau lihat siapa itu!)

Pada Kutpan 5 terdapat kalimat cobo kau tengok sapo tu! merupakan tuturan lisan bahasa Melayu Jambi Kumpeh, ditandai dengan penanda kesantunan coba sesuai dengan pendapat Rahardi (2005: 83). Cobo yang berarti coba, kau tengok berarti kau lihat, sapo berarti siapa, dan tu berarti itu. Jadi, pemakaian penanda kesantunan coba pada kalimat "cubo kau tengok sapo tu!" merupakan penanda bahwa kalimat tersebut termasuk kalimat imperatif suruhan.

Pada kalimat cobo kau tengok sapo tu! terdapat lokusi yaitu penutur mengatakan melihat siapa yang dating sedangkan ilokusi pada kalimat tersebut yaitu penutur menyuruh mitra tutur agar melihat siapa yang datang. Lokusi dan ilokusi pada kalimat tersebut menuntut terjadinya perlokusi, dimana mitra tutur diminta untuk melakukan perintah oleh penutur. Hal ini sesuai dengan teori Yule (dalam terj. Wahyuni, 2006: 83-84) yang mengatakan bahwa perlokusi adalah suatu tindak tutur untuk mempengaruhi mitra tutur untuk melakukan sesuatu.

\section{SIMPULAN}

Berdasarkan hasil penelitian dan pembahasan, maka dapat disimpulkan bahwa terdapat tuturan kalimat imperatif bahasa Melayu Jambi Kumpeh. Kalimat imperatif terdiri dari lima yaitu, kalimat imperatif biasa yang isinya memuat perintah secara langsung untuk melakukan sesuatu, dapat berkisar antara imperatif yang sangat halus dan yang sangat kasar, biasanya ditandai dengan berintonasi keras, didukung dengan kata kerja dasar dan berpartikel pengeras- lah. Kalimat imperatif permintaan yaitu kalimat perintah dengan suruhan yang sangat halus ditandai dengan penanda kesantunan tolong, coba, harap dan mohon. Kalimat imperatif pemberian izin yaitu untuk memberikan izin kepada seseorang yang ditandai dengan penanda kesantunan silakan, dan biarlah. Kalimat imperatif ajakan yaitu kalimat imperatif yang sifatnya untuk mengajak seseorang dengan penanda kesantunan ayo, coba, dan harap. Selanjutnya kalimat imperatif suruhan yaitu kalimat perintah untuk menyuruh seseorang biasanya di tandai dengan penanda kesantunan ayo, coba, tolong, dan silahkan.

Pada penelitian analisis bentuk kalimat imperatif dalam tuturan lisan bahasa Melayu Jambi Kumpeh terdapat tindak tutur. Tindak tutur merupakan suatu tuturan yang disampaikan oleh penutur kepada mitra tutur, tindak tutur terdiri dari tiga yaitu tindak tutur lokusi yaitu tindak tutur menyatakan sesuatu, tindak tutur ilokusi yaitu melakukan tindakan dalam mengatakan sesuatu dan perlokusi yaitu suatu tindak tutur untuk mempengaruhi mitra tutur untuk melakukan sesuatu.

Berdasarkan hasil penelitian, dapat diketahui bahwa kalimat imperatif merupakan kalimat perintah. Kalimat imperatif terbagi menjadi lima dan di dalam kalimat imperatif bahasa Melayu Jambi Kumpeh terdapat tindak tutur lokusi, ilokusi dan perlokusi.

\section{DAFTAR PUSTAKA}

Alwi, Hasan, dkk. (2003). Tata Bahasa Baku Bahasa Indonesia. Jakarta. Balai Pustaka.

Chaer, Abdul. (2007). Linguistik Umum. Jakarta: Rineka Cipta. 
Finoza, Lamuddin. (2008). Komposisi Bahasa Indonesia. Jakarta: Diksi Insan Mulia.

Kosasih, E. (2010). Tata Bahasa Indonesia Praktis. Jakarta: Nobel Edu Media.

Leech, Geoffrey. (penerjemah) M. D. D Oka. (1993). Prinsip-prinsip Pragmatik. Jakarta: Penerbit Universitas Indonesia (UI-Press).

Mahsun, M.S. (2007). Metode Penelitian Bahasa. Jakarta: PT Raja Grafindo Persada.

Moleong, Lexy J. (2017). Metodologi Penelitian Kualitatif. Bandung: PT Remaja Rosdakarya.

Pateda, Mansoer. (2011). Linguistik Sebuah Pengantar. Bandung: Angkasa.

Ramlan. (2005). Ilmu Bahasa Indonesia Sintaksis. Yogyakarta: CV "Karyono".

Rahardi, Kunjana. (2005). Pragmatik Kesantunan Imperatif Bahasa Indonesia. Jakarta: Erlangga.

Rahardi, Setyaningsih, dkk. (2016). Pragmatik

Fenomena

Ketidaksantunan Berbahasa.

Jakarta: Erlangga.

Sugiyono. (2007). Metode Penelitian Pendidikan. Bandung: Alfabeta.

Widjono. (2007). Bahasa Indonesia Perguruan Tinggi. Jakarta: Gramedia Widia sarana Indonesia.

Yule, George. Indah Fajar Wahyuni (penerjemah). (2006). Pragmatik. Yogyakarta: Pustaka Belajar.

Rofii, Afif. dan Hasibuan, Rizka Rani (2019) Interferensi Bahasa Batak Mandailing dalam Tuturan Berbahasa Indonesia Pada Acara Parpunguan Masyarakat Mandailing Kota Jambi. Aksara. Aksara: Jurnal Ilmiah Pendidikan Bahasa dan Sastra Indonesia Vol. 3 No. 1 April 2019 aksara.unbari.ac.id/index.php/aks ara/article/download/94/50.

Rofii, Afif (2015) An Analysis Of Syntactical Ability Of Second Language Children Age 5-6 Years Old In Taman KanakKanak (TK) Para Bintang Kota Jambi. Jurnal Ilmiah Dikdaya Universitas Batanghari Jambi. dikdaya.unbari.ac.id/index.php/di kdaya/article/download/38/38

Analisis Kalimat Imperatif pada Tuturan Masyarakat Desa Teluk Raya Kecamatan Kumpeh Kabupaten Muaro Jambi (Kajian Pragmatik) 